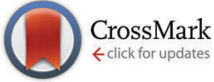

Cite this: New J. Chem., 2016, 40, 7671

Received (in Montpellier, France) 28th January 2016 Accepted 7th July 2016 DOI: 10.1039/c6nj00298f

www.rsc.org/njc

\title{
Modulating the thermal properties of poly(hydroxybutyrate) by the copolymerization of rac- $\beta$-butyrolactone with lactide $\dagger$
}

\author{
Jenny Fagerland, ${ }^{a}$ Anna Finne-Wistrand ${ }^{a}$ and Daniela Pappalardo*ab
}

\begin{abstract}
Biobased poly(hydroxybutyrate) is produced by microorganisms under controlled conditions. It is a linear, high molecular weight, fully isotactic and highly crystalline polymer. However, it has poor mechanical and thermal properties. We have modulated the thermal properties of this material by ring-opening co-polymerization of rac- $\beta$-butyrolactone $(B L)$ with lactide $(L A)$ in the presence of salan-based yttrium and aluminum catalysts. The prepared poly(hydroxybutyrate-co-lactide) copolymers were characterized by proton and carbon nuclear magnetic resonance $\left({ }^{1} \mathrm{H}\right.$ and $\left.{ }^{13} \mathrm{C} N M R\right)$, size exclusion chromatography (SEC) and differential scanning calorimetry (DSC) analyses. The salan-yttrium compound was a more effective catalyst compared to the aluminum compound, affording high molecular weight copolymers with higher monomer conversion and a monomodal distribution of the molecular weights. The kinetic experiments showed a higher rate of polymerization for the LA with respect to the BL. The copolymers were amorphous and DSC showed unique transition temperatures for all of the samples. The formation of a gradient copolymer is proposed.
\end{abstract}

\section{Introduction}

Aliphatic polyesters are currently attracting growing scientific interest as biodegradable and biocompatible materials, and they are finding large applications in various fields, including agricultural, pharmaceutical and biomedical fields.

Poly(hydroxybutyrate) (PHB) belongs to the family of thermoplastic polyesters, and the commercially available PHB is produced by bacteria through the fermentation of carbohydrates under controlled conditions. PHB is a linear, high molecular weight, fully isotactic and highly crystalline polymer, which has mechanical and physical properties similar to some commodity polymers, i.e., poly(ethylene terephthalate). ${ }^{1}$ Although poorly studied for biomedical applications because it is biodegradable, PHB has high potential to be integrated and processed within tissues. $^{2,3}$ The major drawbacks of PHB are its poor mechanical properties, low solubility in some common solvents, slow degradation rate, high cost associated with the bacterial production, and melting temperature, which is too close to the thermal degradation temperature. As a consequence, recent efforts have been devoted

\footnotetext{
${ }^{a}$ Fiber and Polymer Technology, KTH Royal Institute of Technology, Stockholm, Sweden

${ }^{b}$ Dipartimento di Scienze e Tecnologie, via dei Mulini 59/A, 82100 Benevento, Italy. E-mail: pappalardo@unisannio.it

$\dagger$ Electronic supplementary information (ESI) available: NMR spectra of aluminium compounds and of polymers; MALDI mass spectra. See DOI: 10.1039/c6nj00298f
}

to developing efficient chemical approaches, as alternatives to the bacterial approach, allowing for control of the thermal and mechanical properties of the material by modulating the chain microstructure. The ring-opening polymerization (ROP) of cyclic esters, such as lactone, lactides and glycolide, in the presence of metal-based initiators, represents the most convenient method for the preparation of aliphatic poly(ester)s with controlled and predictable molecular weights, stereochemistry, and end groups. ${ }^{4}$ The preparation of atactic, isotactic-enriched and syndiotactic-enriched PHBs has also been achieved by the ROP of commercially available racemic $\beta$-butyrolactone (BL) in the presence of the appropriate catalysts or initiators. ${ }^{5}$ In this regard, we described yttrium amido complexes bearing quadridentate binaphthyl-bridged Schiff-base salen-like and diamine bisphenolate salan-like ligands affording syndiotactic-enriched PHB, which showed modulated thermal properties depending on the degree of stereoregularity of the polymeric chains. ${ }^{6}$ Thomas et al. defined a straightforward synthesis of efficient syndiospecific yttrium salan-based catalysts by the in situ mixing of yttrium(III) isopropoxide and the salan ligand. ${ }^{7}$

The copolymerization of different monomers offers a way to match different polymeric materials. The synthesis of copolymers of various molecular weights, compositions and architectures has led to the ability to enlarge the library of new materials with unique properties. In addition to the control of the stereochemical microstructure, the copolymerization represents another way to control the physical properties of the polymeric materials. 
By varying the composition, monomer sequencing, and molecular weight, the polymer microstructure can be tailored for specific applications, where a proper balance between the mechanical properties, thermal properties and degradation rate is needed. For example, the properties of biodegradable and biocompatible poly(lactide) (PLA), which has found several applications in the pharmaceutical, medical, and agricultural fields, ${ }^{1}$ have been modulated by the copolymerization of the monomer, LA, with several cyclic esters, such as caprolactone, valerolactone and glycolide. ${ }^{4 b}$ Because PLA has good mechanical and thermal properties as well as higher degradation rates with respect to $\mathrm{PHB}$, the ring-opening co-polymerization of BL with LA may be a suitable and promising approach to modulate the poly(hydroxybutyrate) microstructure and, as a consequence, the thermal properties.

Examples of the copolymerization of LA with $\mathrm{BL}$ are rare. ${ }^{8}$ Copolymerization of LA with BL has been described in the presence of catalysts based on main group metals. The ringopening copolymerization of BL with $(S, S)$-lactide was reported in the presence of stannoxane catalysts. ${ }^{8 a}$ Aluminum-based catalysts, bearing salan and salen ligands, have also been described for BL/L-LA copolymerization. ${ }^{8 b, c}$ The synthesis of related block-copolymers by one-pot cationic polymerization has been reported. ${ }^{8 d}$ Starshaped and triblock PHB/PLA copolymers were synthetized with dinuclear indium catalysts. ${ }^{8 e}$

An interesting alternative for the BL/LA copolymerization could be the use of yttrium complexes, which are among the most efficient catalysts for the ROP of cyclic esters as well as for the polymerization of BL to high molecular weight, syndiotactic-enriched PHB. ${ }^{5 a-c, 6,7}$ Herein, we describe the use of a salan-based yttrium isopropoxide catalyst, previously synthetized by Thomas et $a l^{7}{ }^{7}$ and the analogous aluminum complex bearing the same tetradentate ligand in the copolymerization of BL and LA. Interestingly, yttrium complexes stabilized by tetradentate salan-type ligands have never been used in the copolymerization of BL with LA. The synthesis and characterization of copolymers of BL with LA in the presence of these catalysts are described and discussed.

\section{Experimental}

\section{Materials}

Unless otherwise stated, all reactions were performed under standard Schlenk conditions, using a Schlenk line or a glovebox.

The salan ligand $N, N^{\prime}$-dimethyl- $N, N^{\prime}$-bis[(3,5-di-t-butyl-2-hydroxyphenyl)methylene]-1,2-diaminoethane ${ }^{9}$ and the yttrium-salan compound $^{7}$ have been synthesized as previously described.

Aluminum isopropoxide was purchased from Sigma-Aldrich and used as received. rac- $\beta$-Butyrolactone (BL) (98\%, Sigma Aldrich) was stirred above calcium hydride for at least 12 hours, then distilled in vacuo and stored above $3 \AA$ molecular sieves inside a glovebox. Toluene (HPLC grade, Fisher) was stirred above calcium hydride for at least 48 hours, distilled from calcium hydride under a nitrogen atmosphere, and then stored above $3 \AA$ molecular sieves. The NMR-solvent chloroform-d (Cambridge Isotope Laboratories) was used as received.
Methanol (technical, VWR), $n$-heptane (99\%, Fisher) and dichloromethane (HPLC grade, Fisher) were also used as received.

\section{Methods}

Nuclear magnetic resonance (NMR) spectroscopy was performed using a BRUKER 400 Ultrashield $^{\mathrm{TM}}$ instrument with an autosampler.

For analysis of the tacticity, ${ }^{13} \mathrm{C}$ NMR spectroscopy was carried out with either the precipitated or the crude product and the characteristic peaks for the triads of the carbonyl group ( $\sim 169 \mathrm{ppm})$ and the methylene group $(\sim 40 \mathrm{ppm})$ as well as for the diad of the methyl group $(\sim 20 \mathrm{ppm})$ were studied.

Size exclusion chromatography (SEC) was performed using a Polymer Laboratory PL-GPC 50 Plus. Chloroform with toluene as an internal standard was used as the solvent.

Thermal analysis of the polymers was performed using a METTLER TOLEDO Differential scanning calorimeter (DSC) with an autosampler under a nitrogen flow. The analysis program is as follows: heating from $-20{ }^{\circ} \mathrm{C}$ to $220{ }^{\circ} \mathrm{C}$ at a heating rate of $10 \mathrm{~K} \mathrm{~min}^{-1}$, holding at $220{ }^{\circ} \mathrm{C}$ for two minutes, cooling to $-20{ }^{\circ} \mathrm{C}$ at a cooling rate of $10 \mathrm{~K} \mathrm{~min}^{-1}$, holding at $-20{ }^{\circ} \mathrm{C}$ for two minutes and reheating to $220{ }^{\circ} \mathrm{C}$ at a heating rate of $10 \mathrm{~K} \mathrm{~min}^{-1}$. Due to the degradation of PHB at temperatures above $180{ }^{\circ} \mathrm{C}$, only results from first heating were considered.

Elemental analysis of the aluminum compound was performed on a Thermo Finningan Flash EA 1112 series C, H, N analyzer in the microanalytical laboratory of the Chemistry and Biology Department of the University of Salerno.

The MALDI mass spectra were recorded in reflector mode using a 4800 MALDI TOF/TOF ${ }^{\mathrm{TM}}$ Analyzer (Applied Biosystem, Framingham, MA, USA), equipped with a Nd:YAG laser $(\lambda=355 \mathrm{~nm})$ and working in positive ion mode. This MALDI TOF instrument is equipped with a laser with a wavelength of $<500$ ps pulse and $200 \mathrm{~Hz}$ repetition rate. The laser irradiance was set slightly above the threshold. 2-(4-Hydroxyphenylazo)benzoic acid (HABA) (0.1 M in THF) was used as a matrix. Appropriate volumes of polymer solution $\left(5-10 \mathrm{mg} \mathrm{mL}^{-1} \mathrm{THF}\right)$ and matrix solution were mixed in order to obtain $1: 1,1: 2$ and $1: 3$ ratios (sample/matrix v/v). $2 \mu \mathrm{L}$ of each sample/matrix mixture was spotted on the MALDI sample holder and slowly dried to allow matrix crystallization. The resolution of the MALDI spectra is about 8000 (FWHM), and the mass accuracy was 100-150 ppm for masses in the range of 1000-2000 Da.

\section{Synthesis of the aluminum-salan compound}

The salan ligand, $N, N^{\prime}$-dimethyl- $N, N^{\prime}$-bis[(3,5-di-t-butyl-2-hydroxyphenyl)methylene]-1,2-diaminoethane, was synthesized by a Mannich condensation from $N, N^{\prime}$-dimethylethylenediamine (99\%), formaldehyde (37 wt\% in water) and 2,4-ditertbutyl phenol as previously described (99\%). ${ }^{9}$

In a glovebox, a Schlenk flask was charged with $524.8 \mathrm{mg}$ of the salan ligand ( $1 \mathrm{mmol}, 1 \mathrm{eq}.), 204.3 \mathrm{mg}$ of aluminum(III) isopropoxide ( $1 \mathrm{mmol}, 1$ eq.) and $10 \mathrm{~mL}$ of dry toluene. The reaction mixture was stirred at $80{ }^{\circ} \mathrm{C}$ for six days. After cooling to room temperature, the solvent was evaporated. The product was dried in vacuo and stored inside the glovebox. The product 
was characterized by proton and carbon nuclear magnetic resonance $\left({ }^{1} \mathrm{H}\right.$ and $\left.{ }^{13} \mathrm{C} \mathrm{NMR}\right)$ and elemental analyses.

${ }^{1} \mathrm{H}$ NMR (400 MHz, chloroform- $d$ ) $\delta 7.24(\mathrm{~d}, J=2.4 \mathrm{~Hz}, 2 \mathrm{H})$, $6.84(\mathrm{~d}, J=2.6 \mathrm{~Hz}, 2 \mathrm{H}), 6.74(\mathrm{~d}, J=2.6 \mathrm{~Hz}, 2 \mathrm{H}), 6.72(\mathrm{~d}, J=2.6 \mathrm{~Hz}$, $2 \mathrm{H}) \mathrm{Ar}-H ; 4.85\left(\mathrm{~d}, J=2.6 \mathrm{~Hz}, 2 \mathrm{H}, \operatorname{ArCH}_{2} \mathrm{~N}\right) ; 4.44(\mathrm{~m}, J=5.8 \mathrm{~Hz}$, $\left.2 \mathrm{H}, \mathrm{OCH}\left(\mathrm{CH}_{3}\right)_{2}\right) ; 4.26\left(\mathrm{~d}, J=12.9 \mathrm{~Hz}, 2 \mathrm{H}, \operatorname{ArCH}_{2} \mathrm{~N}\right) ; 3.98$ $\left(\mathrm{m}, J=5.8 \mathrm{~Hz}, 1 \mathrm{H}, \mathrm{OCH}\left(\mathrm{CH}_{3}\right)_{2}\right) ; 3.95(\mathrm{~d}, J=12.4 \mathrm{~Hz}, 1 \mathrm{H}), 3.54$ (d, $J=12.3 \mathrm{~Hz}, 1 \mathrm{H}), 3.48$ (d, $J=13.0 \mathrm{~Hz}, 1 \mathrm{H}), 3.41$ (d, $J=13.4 \mathrm{~Hz}$, 2H) $\mathrm{ArCH}_{2} \mathrm{~N}$; 3.04-2.73 (complex m, broad, $4 \mathrm{H}$ ) $\mathrm{CH}_{2} \mathrm{CH}_{2}$; $2.54(\mathrm{~s}, 6 \mathrm{H}), 2.53(\mathrm{~s}, 3 \mathrm{H}), 2.38(\mathrm{~s}, 3 \mathrm{H}), \mathrm{NCH}_{3} ; 1.53(\mathrm{~s}, 9 \mathrm{H}), 1.51$ (s, $9 \mathrm{H}), 1.40(\mathrm{~s}, 9 \mathrm{H}), 1.31(\mathrm{~s}, 9 \mathrm{H}) 1.30(\mathrm{~s}, 18 \mathrm{H}), 1.28(\mathrm{~s}, 18 \mathrm{H})$, $\mathrm{C}\left(\mathrm{CH}_{3}\right)_{3} ; 1.05(\mathrm{~d}, J=5.9 \mathrm{~Hz}, 12 \mathrm{H}), 0.95(\mathrm{~d}, J=5.9 \mathrm{~Hz}, 3 \mathrm{H}), 0.83$ $(\mathrm{d}, J=5.9 \mathrm{~Hz}, 3 \mathrm{H}), \mathrm{OCH}\left(\mathrm{CH}_{3}\right)_{2}$.

${ }^{13} \mathrm{C}$ NMR (75 MHz, chloroform- $d$ ) $\delta$ 157.04, 156.47, 156.11 (ArC-O); 138.31, 138.22, 138.02, 137.76, 137.33, $136.49\left(\mathrm{ArC}_{-}-\mathrm{CMe}_{3}\right)$; 123.80, 123.65, 123.58, 123.37, 123.13, $122.78(\mathrm{ArCH}) ; 121.26$, 119.80, 118, 48 (ArC $\left.C_{\text {ipso }}\right) ; 64.79,64.29,62.77$ (br) $\left(\mathrm{CH}_{2}\right) ; 62.24$, $62.07\left(\mathrm{OCH}\left(\mathrm{CH}_{3}\right)_{2}\right) ;$ 60.84, 56.47, $54.17(\mathrm{br}), 52.22\left(\mathrm{CH}_{2}\right) ; 46.10$, 45.14, $44.25\left(\mathrm{NCH}_{3}\right)$; 35.33, 35.06, 34.86, 34.03, 33.95, 33.93 $\left(\mathrm{C}\left(\mathrm{CH}_{3}\right)_{3}\right) ; 31.83,31.78,29.96,29.92,29.87,29.72\left(\mathrm{C}\left(\mathrm{CH}_{3}\right)_{3}\right)$; 28.15, 27.91, $27.30\left(\mathrm{OCH}\left(\mathrm{CH}_{3}\right)_{2}\right)$.

Anal. calcd for $\mathrm{C}_{37} \mathrm{H}_{61} \mathrm{AlN}_{2} \mathrm{O}_{3} \mathrm{C}, 72,99 ; \mathrm{H}, 10,1 ; \mathrm{N}, 4,60$. Found C 73,45; H, 10,67; N, 4,43.

\section{Polymerization tests}

In a glove box, selected amounts of BL, LA, toluene and catalyst were added into a glass vial equipped with a magnetic stirrer and sealed with a screw-on lid. The vial was then poured into an oil bath and stirred at the desired temperature. After the desired time, the reaction was quenched by the addition of dichloromethane. The product was precipitated in heptane, filtered and dried in a vacuum oven.

\section{Kinetics analysis}

The BL, L-lactide (L-LA), toluene and the catalyst were added into a screw vial inside the glove box. The mixture was stirred at $25{ }^{\circ} \mathrm{C}$. A single drop of the crude product was taken at definite time intervals, poured into $\mathrm{CDCl}_{3}$ and analyzed by ${ }^{1} \mathrm{H}$ NMR. The reaction conditions are as follows: $[\mathrm{Y}]=3 \mathrm{M},[\mathrm{LA}]:[\mathrm{BL}]:[\mathrm{Y}]=$ $90: 90: 1$, toluene as solvent, and $T=25{ }^{\circ} \mathrm{C}$. The same sets of experiments were performed in the presence of D-lactide (D-LA).

\section{Results and discussion}

\section{Synthesis of the catalysts}

Aluminum alkyl or alkoxide derivatives stabilized by salen- or salan-type ligands have been largely described for the stereocontrolled polymerization of rac-lactide. ${ }^{10}$ The catalytic behavior of the aluminum complexes bearing tetradentate ligands strongly depended on the architecture of the ancillary ligand. In detail, besides isotactic PLA obtained from enantiomerically pure L- or D-LA, the preparations of heterotactic, ${ }^{10 a}$ syndiotactic, ${ }^{10 b}$ stereo-block isotactic ${ }^{10 c-e}$ and stereo-gradient isotactic ${ }^{10 f, g}$ PLAs have been described.
Notably, Gibson et al. noticed a remarkable range of microstructures achievable by changing the steric bulk at the ortho position of the phenolate ligands. Moreover, when the size of the phenoxide alkyl substituent increases (from $\mathrm{H}$ to $\mathrm{Me}$ to $t \mathrm{Bu}$ ), the rate of polymerization of the LA decreases. ${ }^{10}$

Given the generally higher reactivity of LA with respect to that of $\mathrm{BL}$ in their copolymerization, ${ }^{8}$ we reasoned that the presence of bulkier substituents in the ortho positions of the phenolate ligand, thus disfavoring the reaction of LA, would probably favor the copolymerization of the two monomers. A similar conceptual approach was successfully pursued by Nomura et al. in the $\varepsilon$-caprolactone/lactide copolymerization in the presence of salen-aluminum based complexes. ${ }^{11}$ With this in mind, a salan ligand bearing tert-butyl groups at the ortho positions of the phenolate ring was selected and used for the preparation of the aluminum isopropoxide and yttrium isopropoxide derivatives.

With respect to the aluminum derivatives, yttrium complexes stabilized by tetradentate salen or salan-type ligands have been far less explored ${ }^{12}$ and have never been used in the copolymerization of BL with LA. The synthesis of the salan-yttrium compound (1) was performed as previously reported. ${ }^{7}$

The synthesis of the salan-aluminum compound (2) was performed by the stoichiometric reaction of the $N, N^{\prime}$-dimethyl$N, N^{\prime}$-bis[(3,5-di-t-butyl-2-hydroxyphenyl)methylene]-1,2-diaminoethane-proligand (Scheme 1) with aluminum isopropoxide in toluene at $80{ }^{\circ} \mathrm{C}$ for 6 days.

The complex was obtained as a white solid in a high yield, and was characterized by ${ }^{1} \mathrm{H},{ }^{13} \mathrm{C}$ NMR, and bi-dimensional NOESY NMR analyses. The ${ }^{1} \mathrm{H}$ NMR spectrum of complex (2) registered at $298 \mathrm{~K}$ in $\mathrm{CDCl}_{3}$ showed the presence of broad signals, probably as a consequence of the flexible nature of the salan ligand and/or the occurrence of fluxional phenomena in solution (Fig. 1).

The ${ }^{1} \mathrm{H}$ NMR spectrum showed the presence of at least two species in approximately a 1:1 ratio. Indeed two methine protons for the isopropoxide group ( $\left.\mathrm{Al}-\mathrm{OCH} \mathrm{Me}_{2}\right)$ appeared as septets at $\delta=4.44$ and $3.98 \mathrm{ppm}$; the corresponding methyl groups appeared as one doublet at $\delta=1.05 \mathrm{ppm}$ and as a double of doublets at $\delta=0.95 \mathrm{ppm}$ and $0.83 \mathrm{ppm}$, respectively. The latter pattern indicated that the two methyl groups are not equivalent and that the ligand could be wrapped around the aluminum in a non-symmetrical way. Of the two species observed, one is symmetric (s), and the other is asymmetric (a). Confirmation of this hypothesis comes from the inspection of the spectrum: indeed one singlet for the methyl groups on the nitrogen (NMe) at $\delta=2.54 \mathrm{ppm}$ appeared for the symmetric species s, while two singlets at $\delta=2.53 \mathrm{ppm}$ and at $\delta=2.49 \mathrm{ppm}$

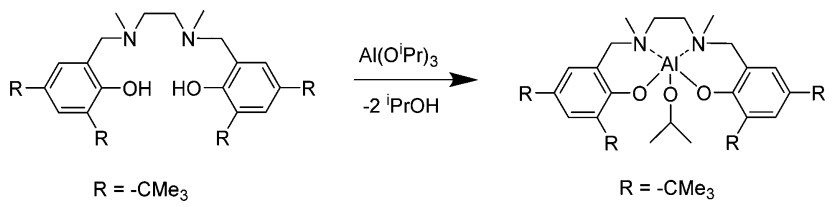

Scheme 1 Synthesis of the salan-aluminum compound (2). 

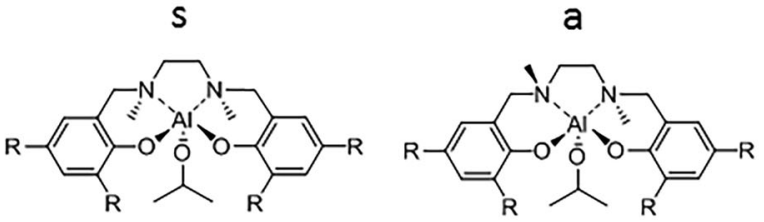

.

appeared for the asymmetric species a. Moreover, 4 signals account for the tert-butyl groups in the a species, while just 2 are found in the symmetric species a. Notably the ratio of the integrals between the total $\mathrm{OCH}\left(\mathrm{CH}_{3}\right)_{2}$ groups and the total NMe groups, indicated a 1:1 ligand: isoproxide molar ratio.

After coordination of the ligand to the aluminum center, the phenoxymethylene protons $\mathrm{ArCH}_{2} \mathrm{~N}$ became diastereomeric and appeared as broad doublets at $\delta=4.85,4.26,3.95,3.54$, 3.48 and $3.41 \mathrm{ppm}$. The flexible nature of the salan ligand framework may be the origin of the presence of at least two species, in fluxional equilibrium, in solution.

In the NMR spectrum of the sample the presence of resonances due to the "free ligand" is observed and it accounts for less than $4 \%$ in weight of the sample. The formation of the free ligand might be due to adventitious water.

The ${ }^{13} \mathrm{C}$ NMR characterization of compound 2, also supported by DEPT135 NMR analysis, confirmed the presence of two species (see ESI $\dagger$ ). Indeed the number of signals observed in the ${ }^{13} \mathrm{C}$ NMR spectrum (i.e. 2 signals for the methine carbon isopropoxide $\mathrm{Al}-\mathrm{OCHMe}, 3$ signals for the methyl groups on the isopropoxide, 3 signals for the NMe carbon, the aromatic carbon pattern) is consistent with the above attribution.

To gain more insight into the nature of these species, a ${ }^{1} \mathrm{H}-{ }^{1} \mathrm{H}$ NOESY spectrum was registered at room temperature (Fig. 2). In the NOESY spectrum, the red cross-peaks (in opposite phase with the diagonal) indicated spatial correlation. The positive blue cross-peaks, with the same phase as the diagonal, indicated chemical exchange processes instead.

For the symmetric species, a NOE effect was observed between the NMe protons at $2.54 \mathrm{ppm}$ and the singlet $\mathrm{Al}-\mathrm{OCHMe}_{2}$ protons at $1.05 \mathrm{ppm}$ (Fig. 2, left), thus indicating that the two equivalent methyl groups on the nitrogen atoms are in a pseudo-cis geometry pointing toward the isoproxide group. In contrast, in the asymmetric species a two $\mathrm{NMe}_{2}$ signals appeared; the NMe protons at $2.49 \mathrm{ppm}$ showed a NOE effect with the two non-equivalent methyl groups in the $\mathrm{Al}-\mathrm{OCHMe}_{2}$ (at 0.95 and $0.83 \mathrm{ppm}$ ). The other NMe protons at $2.49 \mathrm{ppm}$ showed a NOE effect with a tert-butyl group on the phenoxide ring. This clearly indicated the pseudo-trans positions of the methyl groups on the nitrogen atoms in the species a. Moreover, positive cross-peaks, with the same phase as the diagonal, also arise. In detail, positive cross-peaks are observed between the different $\mathrm{ArCH}_{2} \mathrm{~N}$ protons as well as between

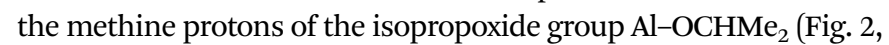
right). It is reasonable to hypothesize that a chemical exchange, which may involve alkoxy-bridged species, is occurring in solution.

\section{Copolymerization of rac- $\beta$-butyrolactone and lactide}

Yttrium complexes are among the most efficient catalysts for the ROP of BL with high molecular weight PHB. ${ }^{5 a-c, 6,7}$

As reported in the literature, the salan-yttrium based catalyst (1) produced syndiotactic enriched PHB (Scheme 2). ${ }^{7}$

The ROP of BL in the presence of the salan-aluminum compound (2) was assessed in a toluene solution under different 

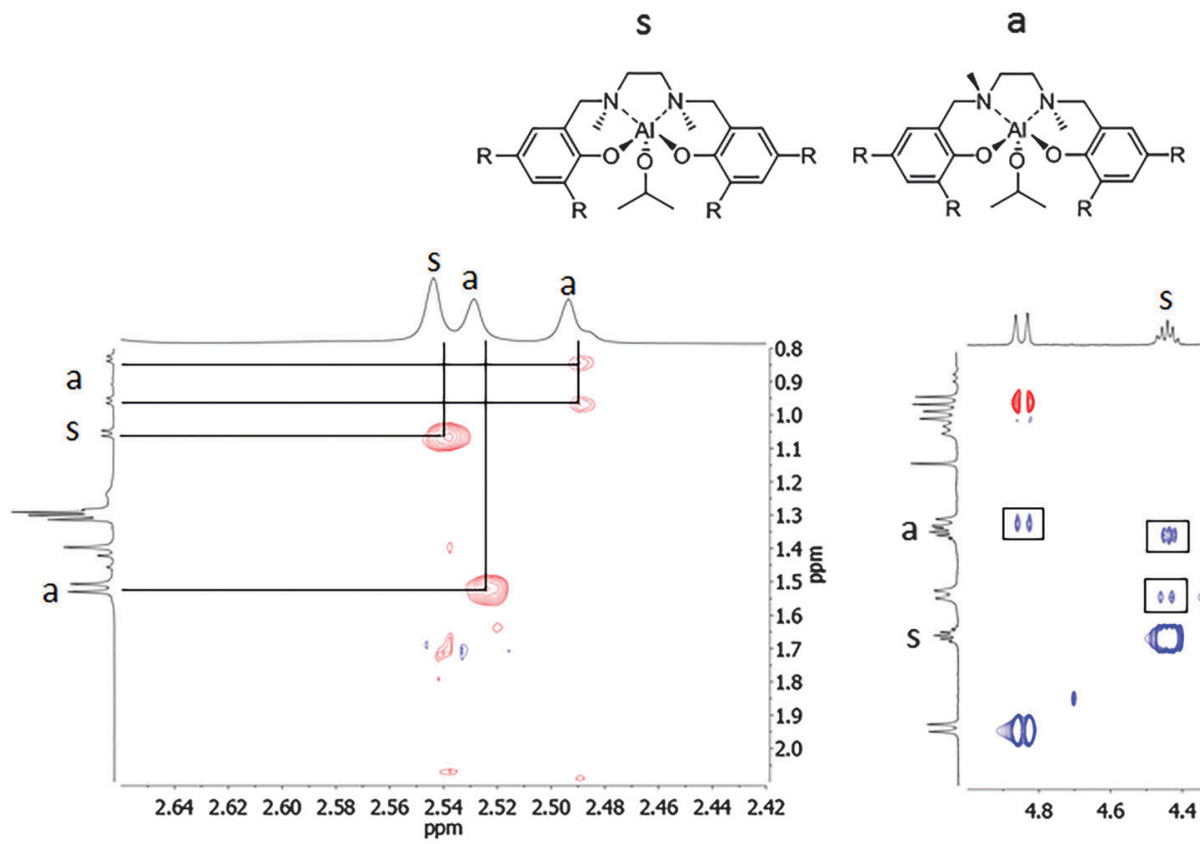

Fig. $2{ }^{1} \mathrm{H}-{ }^{1} \mathrm{H}$ NOESY spectrum of the salan-aluminum compound (2) in $\mathrm{CDCl}_{3}$ at $25^{\circ} \mathrm{C}$. The cross-peaks in phase with the diagonal are indicated with a square.

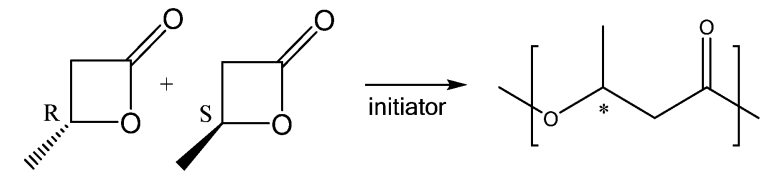

Scheme 2 ROP of rac- $\beta$-butyrolactone.

experimental conditions, by systematically changing the temperature, time, amount of solvent, and monomer/catalyst molar ratio. The products were characterized by NMR, SEC and DSC analysis. The salan-aluminum compound (2) catalyzes the ROP of BL with PHB, with a conversion of $72 \%$ in 70 hours at $70{ }^{\circ} \mathrm{C}$. The polymer was atactic, as determined by the ${ }^{13} \mathrm{C}$ NMR analysis in the carbonyl and methylene regions (see ESI $\dagger$ ). Both in the methylene and in the carbonyl regions, the four resonances attributed, according to the literature, to the triads $r m, m m, r r$, and $m r$ showed roughly equally intensities. The probability of racemic linkages between monomer units was $P r=0.54 .^{13}$

Copolymerization of BL with LA was performed in the presence of the salan-based-yttrium and aluminum compounds ( 1 and 2 ), by varying the polymerization conditions (Scheme 3 ).

The polymers were characterized by ${ }^{1} \mathrm{H}$ and ${ }^{13} \mathrm{C}$ NMR, SEC and DSC. The results of the NMR and SEC characterization are shown in Table 1.

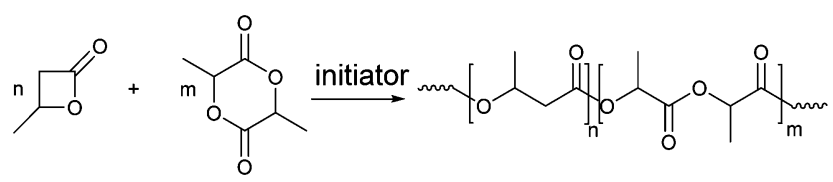

Scheme 3 Synthesis of poly(3-hydroxybutyrate)-co-poly(lactide).
Polymerization in the presence of salan-yttrium proceeded with a good yield in 2 hours even at $20^{\circ} \mathrm{C}$, with almost complete conversion of LA (99\%). Reactions with the salan-aluminum compound, instead, were very slow, and the conversion of both monomers was approximately $50 \%$ after six days. The conversion of BL depended on the amount of salan-yttrium catalyst being used; when the concentration was $1.5 \mathrm{~mol} \mathrm{~L}^{-1}$, the conversion was never higher than $39 \%$, but the conversion increased as the catalyst concentration increased. The average molecular weights of the copolymers, measured by SEC, were also strongly dependent on the catalyst. Monomodal distributions were always observed. When salan-yttrium was used, molecular weights from 16000 to $48000 \mathrm{~g} \mathrm{~mol}^{-1}$ were obtained with a polydispersity index between 1.09 and 1.65. With salan-aluminum lower molecular weights of approximately $9900 \mathrm{~g} \mathrm{~mol}^{-1}$ were obtained as well as a very low dispersity index (1.05).

The synthesis was performed at the following three different reaction temperatures: 20,50 and $70{ }^{\circ} \mathrm{C}$. The highest molecular weight was obtained when the temperature was set to $20{ }^{\circ} \mathrm{C}$ but at the same time the number of hetero-sequences (\% in mol) was low $(20-34 \%)$. The highest number of hetero-sequences (57\%) was obtained when the highest reaction temperature $\left(70{ }^{\circ} \mathrm{C}\right)$ was used. At high concentrations, the conversion and incorporation of BL increased. The amount of solvent also affected the average molecular weight of the copolymers; at low concentrations the molecular weight increased and a high concentration resulted in a lower molecular weight. This effect is probably related to monomer diffusion.

The molar feed ratio did not correspond to the conversion of BL and LA or the composition of the copolymer. The LA was preferentially incorporated into the copolymer with respect to BL. However, the polymerization runs performed at different feed ratios demonstrated the possibility of modulating the 
Table 1 Copolymerization of BL and LA

\begin{tabular}{|c|c|c|c|c|c|c|c|c|c|c|c|c|c|c|}
\hline \multirow[b]{2}{*}{ Entry $^{a}$} & \multirow{2}{*}{$\begin{array}{l}\text { L-LA, D-LA, } \\
r a c \text {-LA }\end{array}$} & \multirow[b]{2}{*}{$T\left[{ }^{\circ} \mathrm{C}\right]$} & \multirow{2}{*}{$\begin{array}{l}\text { Cat }\left[\times 10^{-2}\right. \\
\left.\mathrm{mol} \mathrm{L}^{-1}\right]\end{array}$} & \multicolumn{3}{|c|}{$\begin{array}{l}\text { Molar feed } \\
\text { ratio [mol] }\end{array}$} & \multicolumn{2}{|c|}{$\begin{array}{l}\text { Conversion }^{b} \\
{[\% \text { in mol }]} \\
\end{array}$} & \multicolumn{2}{|c|}{$\begin{array}{l}\text { Composition }^{b} \\
{[\% \text { in mol] }} \\
\end{array}$} & \multirow{2}{*}{$\begin{array}{l}\text { Hetero-sequences }{ }^{b} \\
{[\% \text { in mol }]}\end{array}$} & \multirow{2}{*}{$\begin{array}{l}\mathrm{Mn}_{\text {theo }} \\
{\left[\mathrm{g} \mathrm{mol}^{-1}\right]}\end{array}$} & \multicolumn{2}{|c|}{$\underline{\text { SEC characterization }}$} \\
\hline & & & & Cat & $\mathrm{BL}$ & LA & $\mathrm{BL}$ & LA & $\mathrm{BL}$ & LA & & & $\mathrm{Mn}$ & 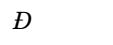 \\
\hline 2 & $\mathrm{~L}$ & 20 & 5.9 & 1 & 78 & 80 & 57 & 99 & 48 & 52 & 31 & 15228 & 24160 & 1.26 \\
\hline 3 & $\mathrm{~L}$ & 50 & 6.0 & 1 & 89 & 92 & 58 & 99 & 34 & 66 & 43 & 17555 & 18826 & 1.65 \\
\hline 4 & $\mathrm{~L}$ & 50 & 3.0 & 1 & 108 & 111 & 72 & 99 & 47 & 53 & 45 & 22512 & 24212 & 1.27 \\
\hline 5 & $\mathrm{~L}$ & 50 & 1.5 & 1 & 109 & 104 & 33 & 99 & 20 & 80 & 85 & 17920 & 35338 & 1.08 \\
\hline 8 & $\mathrm{~L}$ & 50 & 3.1 & 1 & 111 & 41 & 26 & 99 & 44 & 56 & 51 & 8327 & 18653 & 1.09 \\
\hline $9^{b}$ & $\mathrm{~L}$ & 50 & 2.7 & 1 & 207 & 239 & 20 & 99 & 17 & 83 & 95 & 37632 & 43073 & 1.09 \\
\hline 10 & $r a c$ & 50 & 3.0 & 1 & 88 & 88 & 66 & 99 & 37 & 63 & 35 & 17540 & 28004 & 1.20 \\
\hline 11 & D & 50 & 3.0 & 1 & 74 & 74 & 79 & 99 & 45 & 55 & 40 & 15577 & 20129 & 1.24 \\
\hline $12^{c}$ & $\mathrm{~L}$ & 70 & 5.8 & 2 & 82 & 89 & 43 & 51 & 40 & 60 & 56 & 9569 & 9891 & 1.05 \\
\hline 13 & L & 20 & 3.0 & 1 & 81 & 37 & 88 & 99 & 64 & 36 & 20 & 11404 & 16462 & 1.09 \\
\hline
\end{tabular}

${ }^{a}$ Polymerization conditions: catalyst $=$ salan-yttrium (1); solvent $=$ toluene; and time $=2$ hours. ${ }^{b}$ The time was 4 hours. The conversion and composition were determined by ${ }^{1} \mathrm{H}-\mathrm{NMR}$ analysis, while the heterosequences, i.e. the percent mol ratio of $[\mathrm{BL}-\mathrm{LA}] /[\mathrm{BL}-\mathrm{BL}+\mathrm{BL}-\mathrm{LA}]$, by ${ }^{1} \mathrm{H}$ and ${ }^{13} \mathrm{C}$ NMR analysis. ${ }^{c}$ The time was 144 hours and the catalyst was salan-aluminum (2).

composition and the molecular weight of the polymers to some extent. Very interestingly, the highest conversion of BL was obtained when D-LA was copolymerized with BL suggesting that the stereochemistry of LA could affect the conversion of BL.

Characterization of the copolymer microstructure was performed by ${ }^{13} \mathrm{C}$ and ${ }^{1} \mathrm{H}$ NMR. In the ${ }^{1} \mathrm{H}$ NMR spectrum of the poly(BL-co-LA) sample, the signals attributable to the PHB and PLLA are recognized (Fig. 3). Interestingly, the methylene hydrogens appeared very sensitive to the chemical environment, and two patterns of doublet of doublets, one relative to the BL-BL homosequences and the other to the BL-LA heterosequences, are recognized to be centered at chemical shifts of 2.55 and $2.71 \mathrm{ppm}$, respectively. The intensities of the signals due to the heterosequences (BL-LA diads) increase by increasing the amount of LA in the copolymer (Fig. 4).

A low molecular weight sample was prepared: the ${ }^{1} \mathrm{H}$ NMR spectrum (see ESI $\dagger$ ) showed the presence of the signals of the hydroxy end groups $\mathrm{HOCH}\left(\mathrm{CH}_{3}\right) \mathrm{CO}-$ at $\delta=4.36 \mathrm{ppm}$ and of $\mathrm{HOCH}\left(\mathrm{CH}_{3}\right) \mathrm{CH}_{2} \mathrm{CO}-$ at $\delta=4.36 \mathrm{ppm}$, probably derived from the<smiles>CC(C)CC(C)OC(C)C(=O)OC(C)C(=O)OC(C)C(=O)C(C)(C)C</smiles>

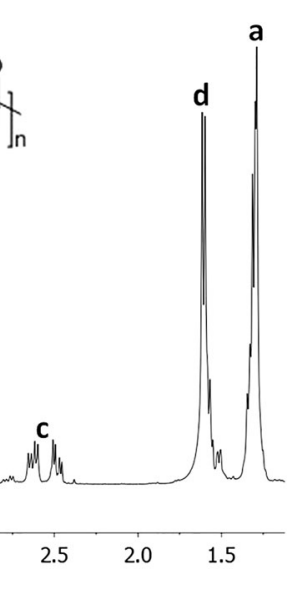

Fig. $3{ }^{1} \mathrm{H}$ NMR spectrum of the poly(3-hydroxybutyrate-co-lactide) sample (Table 1, entry 2) in $\mathrm{CDCl}_{3}$ at $25^{\circ} \mathrm{C}$.

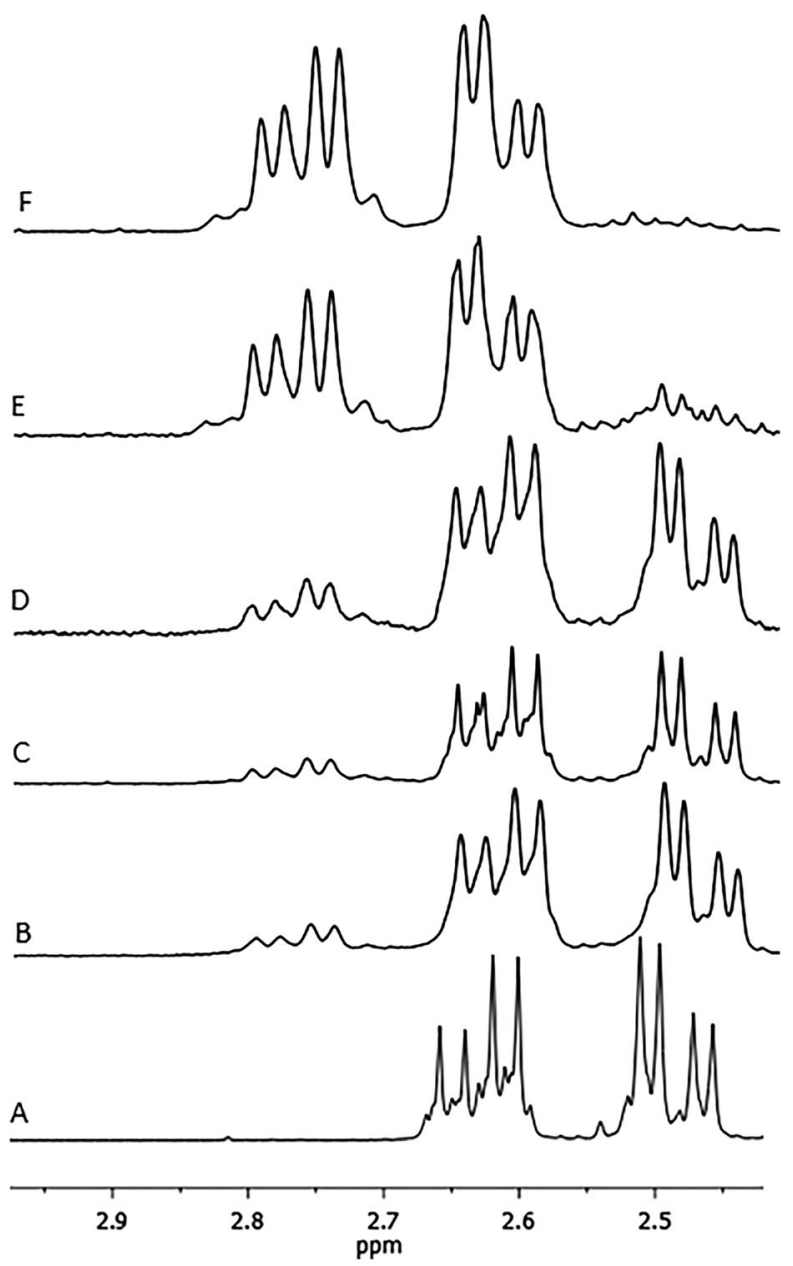

Fig. 4 Methylene regions of the ${ }^{1} \mathrm{H}$ NMR spectra of the poly(3-hydroxybutyrate-co-lactide) samples with different monomer compositions: $\mathrm{A}$ is a PHB homopolymer, B is entry 2, C is entry 4, D is entry $1, E$ is entry 5 and F is entry 9 (Table 1). 
hydrolysis of a growing chain ending, respectively, with a lactyl unit and a butyrate unit. ${ }^{14 a, b}$ The ratio between the two signals was $1: 6$, thus indicating that the copolymeric chains ended preferentially with a butyrate unit, since the lactide monomer was presumably consumed first.

MALDI-TOF MS analysis of the sample of entry 12 was carried out, and confirmed the copolymeric nature, as well as the presence of hydroxy end groups. Moreover sequences of even numbers of repetitive lactyl units were also observed, thus indicating the occurrence of transesterification reactions. However the MALDI MS spectrum obtained does not depict the entire sample but the less abundant lower molecular weight fraction (see ESI $\dagger$ ).

More details on the copolymer microstructure are derived from the ${ }^{13} \mathrm{C}$ NMR spectrum. The attribution has been performed according to the literature. ${ }^{8 a}$ Having designated $\mathrm{L}$ as a lactyl unit and $\mathrm{B}$ a butyrate unit, the signals relative to the LLL and BBB homosequences were recognized. Moreover, signals due to the $\mathrm{BL}$ heterosequences are also recognized and attributed to the proper sequence according to the literature ${ }^{8 a}$ (Fig. 5).

Characterization of the microstructure of poly(BL-co-LA) was completed by the $2 \mathrm{D}$ HMBC ${ }^{1} \mathrm{H}-{ }^{13} \mathrm{C}$ correlation NMR spectrum. As shown in Fig. 6, a correlation cross-peak between the butyrate methylene protons and the methine carbon of the LA relative to the sequence LLB appeared.

The overall data showed that LA and BL are copolymerized by both of the catalysts, with salan-yttrium being more efficient. The heterosequences are also observed with high frequency, while the copolymers were always more rich in LA.

To gain more insights into the copolymerization, kinetic studies were also performed (Fig. 7). Monitoring of the copolymerization reactions of salan-yttrium with BL and L-LA or D-LA, performed by ${ }^{1} \mathrm{H}$ NMR, disclosed that the rate of LA polymerization was significantly higher than that of BL. Interestingly in

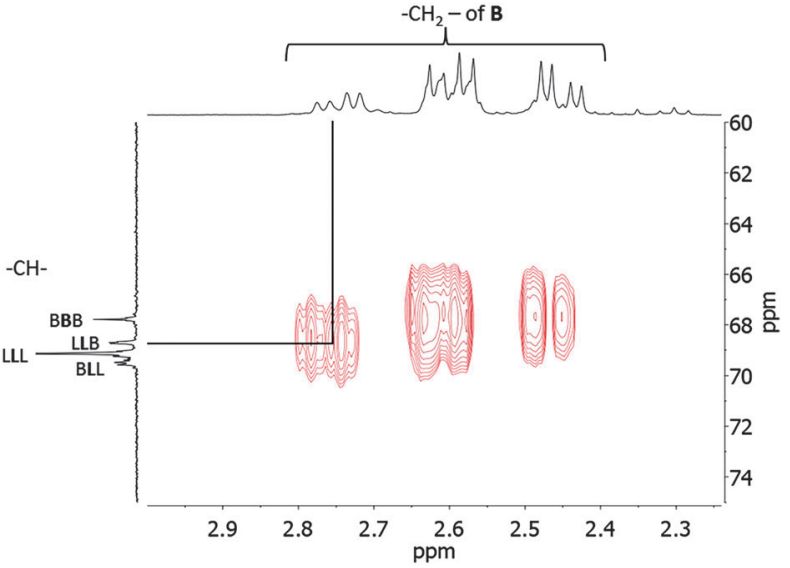

Fig. 6 2D $\mathrm{HMBC} \quad{ }^{1} \mathrm{H}-{ }^{13} \mathrm{C}$ correlation NMR spectrum of the poly(hydroxybutyrate-co-lactide) sample (Table 1, entry 3).

the copolymerization with $\mathrm{D}-\mathrm{LA}$, the rate of $\mathrm{BL}$ polymerization was faster (Fig. 8).

The conversion rate of $\mathrm{BL}$ in the copolymerization with $\mathrm{D}-\mathrm{LA}$ was twice as fast as that of the copolymerization of BL and L-LA. This behavior is most likely due to some stereochemical preference in the salan-yttrium catalyst.

Due to the different rates of the copolymerization with the two monomers, the formation of gradient copolymers is proposed, where the composition changes gradually from predominantly sequences of one comonomer to the other as a function of the copolymer chain length. Similar results were obtained by Shaver et al. in the copolymerization of LA and BL in the presence of different salan-aluminum catalysts. ${ }^{8 c}$

The thermal properties of the copolymers were analyzed by DSC (Table 2). The thermograms showed only one glass transition

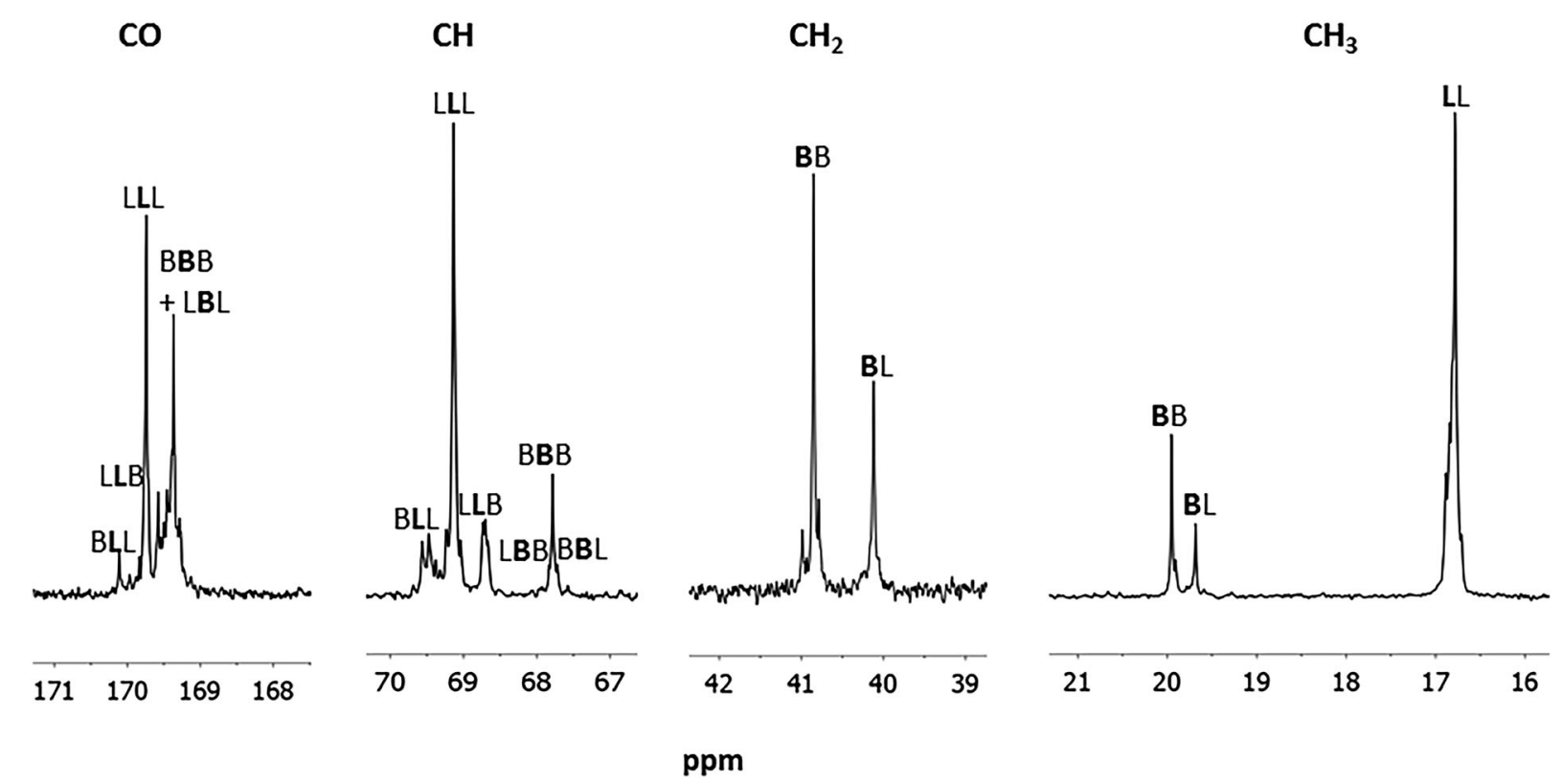

Fig. $5{ }^{13} \mathrm{C}$ NMR (selected regions) spectrum of the poly(hydroxybutyrate-co-lactide) (Table 1, entry 2 ) in $\mathrm{CDCl}_{3}$ at $25^{\circ} \mathrm{C}$. 

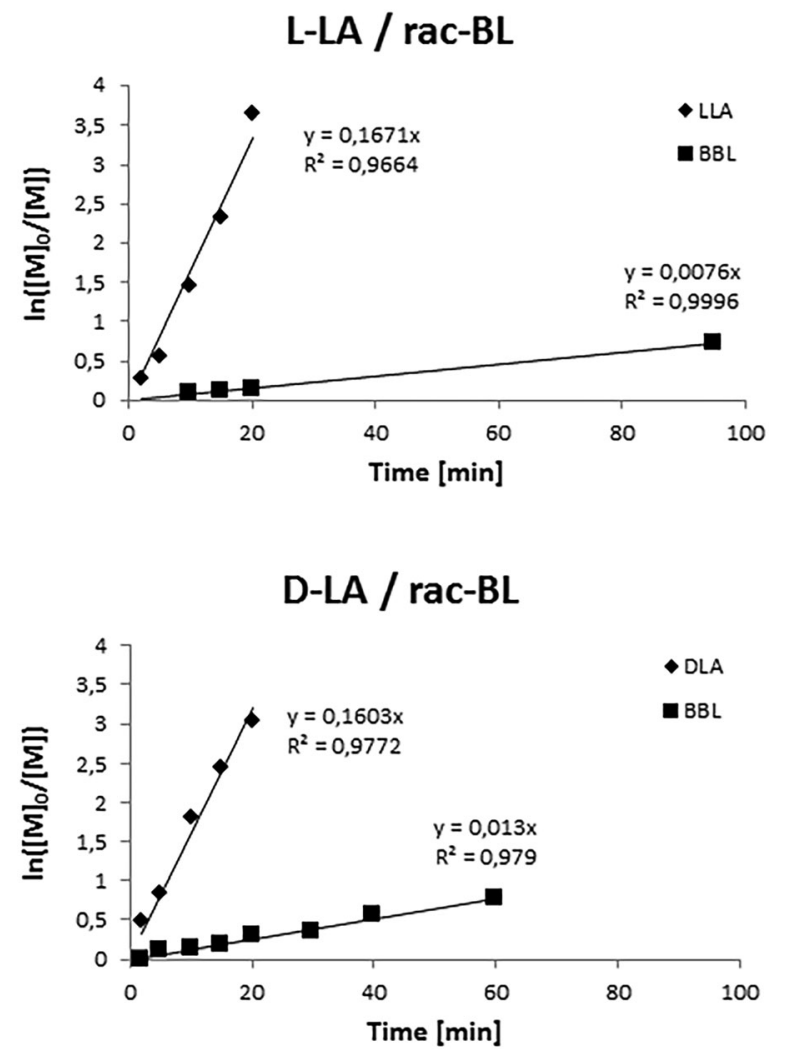

Fig. 7 Pseudo-first-order kinetic plots for the ROP of $\mathrm{LA}$ and rac-BL promoted by salan-yttrium. Reaction conditions: $[\mathrm{Y}]=3 \mathrm{M}$; $[\mathrm{LA}]$ : $[\mathrm{BL}]$ : $[Y]=90: 90: 1$; toluene as solvent; and $T=25^{\circ} \mathrm{C}$.

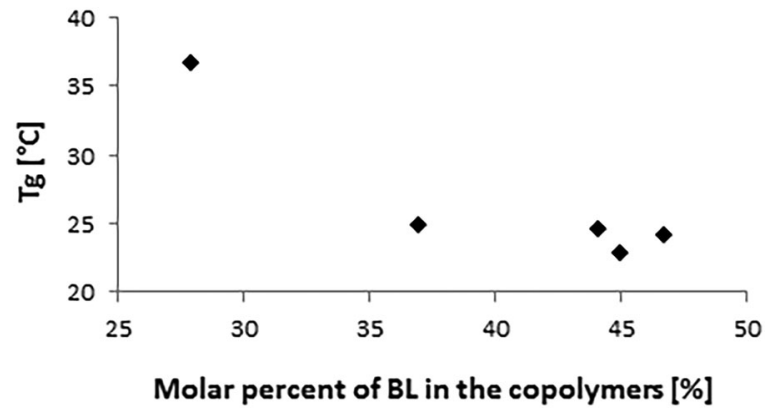

Fig. 8 Plot of $T_{\mathrm{g}}$ versus the molar percentage of $\mathrm{BL}$ in the copolymers.

Table 2 The composition of $\mathrm{BL}$ and $\mathrm{LA}$ in the copolymers and their corresponding $T_{\mathrm{g}}$

\begin{tabular}{lllll}
\hline & & \multicolumn{2}{l}{ Composition } & \\
\cline { 3 - 4 } Entry $^{a}$ & Cat/LA & BL $[\%]$ & LA [\%] & $T_{\mathrm{g}}\left[{ }^{\circ} \mathrm{C}\right]$ \\
\hline 4 & $\mathrm{Y} / \mathrm{L}$ & 47 & 53 & 24.1 \\
10 & $\mathrm{Y} / \mathrm{rac}$ & 37 & 63 & 24.8 \\
11 & $\mathrm{Y} / \mathrm{D}$ & 45 & 55 & 22.8 \\
7 & $\mathrm{Y} / \mathrm{L}$ & 28 & 72 & 36.7 \\
8 & $\mathrm{Y} / \mathrm{L}$ & 44 & 56 & 24.5
\end{tabular}

${ }^{a}$ For the polymerization conditions and polymer features, see Table 1 . temperature $\left(T_{\mathrm{g}}\right)$ for each sample, while no melting temperature was detected. The $T_{\mathrm{g}}$ decreased by increasing the molar percentage of BL in the copolymers (Fig. 8). The polymers were fully amorphous, which suggests that there was no phase separation.

\section{Conclusions}

Copolymerization of different monomers opens the way to the synthesis of materials having improved and modulated properties with respect to the parent homo-polymers.

We have shown that salan-yttrium is able to promote the copolymerization of rac- $\beta$-butyrolactone (BL) and lactide (LA) to high molecular weight copolymers with good control and a monomodal distribution of the molecular weights. The results showed that salan-yttrium was a more effective catalyst compared to salan-aluminum, allowing the preparation of high molecular weight copolymers with a higher monomer conversion. Indeed almost complete conversion of LA was obtained in all reactions when salan-yttrium was used. The NMR characterization showed large amounts of heterosequences and a larger incorporation of $\mathrm{LA}$ with respect to BL. The incorporation of BL could be improved by increasing the temperature and adjusting the catalyst concentration. The composition of BL and LA in the copolymer could be modulated to some extent by the molar feed ratio. Interestingly, when D-LA was used instead of L-LA the conversion of BL was $79 \%$ and the molar feed ratio corresponded much better to the composition of the copolymer.

The kinetic experiments showed a faster incorporation of LA with respect to BL, while the thermal analysis showed a single glass transition temperature $\left(T_{\mathrm{g}}\right)$ for all of the samples. The $T_{\mathrm{g}}$ could be modulated by varying the molar percentage of BL in the copolymer. The above data are consistent with the formation of a gradient copolymer. As recently outlined, such gradient copolymers may be "superior to traditional block polymers for many applications, but few methods are available for synthesizing such polymers." These materials may exhibit promising features for applications in the biomedical field.

\section{Acknowledgements}

The authors acknowledge VINNOVA, Mobility for Growth, the Marie Curie Actions FP7-PEOPLE-2011-COFUND (GROWTH 291795) and the Swedish Research Council (Grant ID 621-2013-3764) for financial support of this work. The authors thank Dr Patrizia Iannece (University of Salerno, Italy) for elemental analysis, and Dr Sabrina Carroccio (Consiglio Nazionale delle Ricerche, Catania, Italy) for MALDI-TOF MS analysis.

\section{Notes and references}

1 H. Wölfle, H. Kopacka, K. Wurst, P. Preishuber-Pflügl and B. Bildstein, J. Org. Chem., 2009, 694, 2493.

2 Y. Poirier, D. E. Dennis, K. Klomparens and C. Somerville, Science, 1992, 256, 520. 
3 M. Zinn, B. Witholt and T. Egli, Adv. Drug Delivery Rev., 2001, 53, 5 .

4 (a) G. Scott and D. Gillead, Degradable Polymers, Chapman \& Hall, 1995; (b) A. C. Albertsson and I. K. Varma, Biomacromolecules, 2003, 4, 1466; (c) Y. Wei, S. Wang and S. Zhou, Dalton Trans., 2016, 45(11), 4471-4485; (d) J.-F. Carpentier, Organometallics, 2015, 34(17), 4175-4189; (e) Modern Organoaluminum Reagents, ed. S. Woodward and S. Dagorne, Topics in Organometallic Chemistry, Springer, Berlin, Heidelberg, 2013, vol. 41; (f) J. P. MacDonald and M. P. Shaver, in Green Polymer Chemistry: Biobased Materials and Biocatalysis, ed. H. N. Cheng, R. A. Gross and P. B. Smith, ACS Symposium Series, American Chemical Society, Washington, DC, 2015, vol. 1192.

5 (a) C. M. Thomas, Chem. Soc. Rev., 2010, 39, 165; (b) A. Le Borgne, C. Pluta and N. Spassky, Macromol. Rapid Commun., 1994, 15, 955; (c) J.-F. Carpentier, Macromol. Rapid Commun., 2010, 31, 1696; (d) M. Zintl, F. Molnar, T. Urban, V. Bernhart, P. Preishur-Pflügl and B. Rieger, Angew. Chem., Int. Ed., 2008, 47, 3458.

6 D. Pappalardo, M. Bruno, M. Lamberti and C. Pellecchia, Macromol. Chem. Phys., 2013, 1965.

7 J. Fang, M. J.-L. Tschan, T. Roisnel, X. Trivelli, R. M. Gauvin, C. M. Thomas and L. Maron, Polym. Chem., 2013, 4(2), 360.

8 (a) H. Abe, Y. Doi, Y. Hori and T. Hagiwara, Polymer, 1998, 39, 59; (b) J. P. MacDonald, M. P. Parker, B. W. Greenland, D. Hermida-Merino, I. W. Hamley and M. P Shaver, Polym. Chem., 2015, 6(9), 1445-1453; (c) E. D. Cross, L. E. N. Allan, A. Decken and M. P. Shaver, J. Polym. Sci., Part A: Polym. Chem., 2013, 51, 1137; (d) M. Basko, A. Duda, S. Kazmierski and P. Kubisa, J. Polym. Sci., Part A: Polym. Chem., 2013, 51, 4873; (e) I. Yu, T. Ebrahimi, S. G. Hatzikiriakos and P. Mehrkhodavandi, Dalton Trans., 2015, 44(32), 14248-14254.

9 E. Y. Tshuva, N. Gendeziuk and M. Kol, Tetrahedron Lett., 2001, 42(36), 6405.
10 (a) P. Hormnirun, E. L. Marshall, V. C. Gibson, A. J. P. White and D. J. Williams, J. Am. Chem. Soc., 2004, 126, 2688; (b) T. M. Ovitt and G. W. Coates, J. Am. Chem. Soc., 1999, 121, 4072; (c) C. P. Radano, G. L. Baker and M. R. Smith, J. Am. Chem. Soc., 2000, 122, 1552; (d) T. M. Ovitt and G. W. Coates, J. Polym. Sci., Part A: Polym. Chem., 2000, 38, 4686; (e) T. M. Ovitt and G. W. Coates, J. Am. Chem. Soc., 2002, 124, 1316; $(f)$ Z. Zhong, P. J. Dijkstra and J. Feijen, Angew. Chem., Int. Ed., 2002, 41, 4510; (g) Z. Zhong, P. J. Dijkstra and J. Feijen, J. Am. Chem. Soc., 2003, 125, 11291-11298; (h) P. Hormnirun, E. L. Marshall, V. C. Gibson, A. J. P. White and D. J. Williams, J. Am. Chem. Soc., 2004, 126, 2688; (i) P. Hormnirun, E. L. Marshall, V. C. Gibson, R. I. Pugh and A. J. P. White, Proc. Natl. Acad. Sci. U. S. A., 2006, 103, 15343.

11 N. Nomura, A. Akita, R. Ishii and M. Mizuno, J. Am. Chem. Soc., 2010, 132(6), 1750-1751.

12 (a) J. W. Kramer, D. S. Treitler, E. W. Dunn, P. M. Castro, T. Roisnel, C. M. Thomas and G. W. Coates, J. Am. Chem. Soc., 2009, 131, 16042; (b) X. Liu, X. Shang, T. Tang, N. Hu, F. Pei, D. Cui, X. Chen and X. Jing, Organometallics, 2007, 26, 2747; (c) E. Grunova, E. Kirillov, T. Roisnel and J.-F. Carpentier, Organometallics, 2008, 27, 5691; (d) D. Pappalardo, M. Bruno, M. Lamberti, M. Mazzeo and C. Pellecchia, J. Mol. Catal. A: Chem., 2013, 379, 303.

13 For comparison purposes, polymerization tests in the presence of the aluminium isoproxide and yttrium isopropoxide precursors were also carried out. Notably, the metal isoproxide precursors produced atactic polymers. The obtained PHB was amorphous, with a glass transition temperature below $0{ }^{\circ} \mathrm{C}$.

14 (a) H. Ma and J. Okuda, Macromolecules, 2005, 38(7), 2665-2673;

(b) L. R. Rieth, D. R. Moore, E. B. Lobkovsky and G. W. Coates, J. Am. Chem. Soc., 2002, 124(51), 15239-15248.

15 R. Zhao and K. J. Shea, ACS Macro Lett., 2015, 4, 58. 